\title{
COMPARATIVE ANALYSIS OF TWO CLASSIFICATION SYSTEMS OF THORACOLUMBAR SPINE FRACTURES
}

\author{
ANÁLISE COMPARATIVA DE DOIS SISTEMAS DE CLASSIFICAÇÃO DE FRATURAS \\ DA COLUNA TORACOLOMBAR \\ ANÁLISIS COMPARATIVO DE DOS SISTEMAS DE CLASIFICACIÓN DE FRACTURAS \\ DE LA COLUMNA TORACOLUMBAR
}

André Luiz Pagotto Vieira, ${ }^{1}$ Juliano Rodrigues dos Santos, ${ }^{1}$ Guilherme Galito Henriques ${ }^{1}$

1. Institute of Orthopedics and Traumatology / Vitoria Apart Hospital, Carapina, ES, Brazil.

\begin{abstract}
Objective: To evaluate the reproducibility and the interobserver coefficient of concordance between the AO/Magerl and AOSpine classifications for thoracolumbar spine fractures. Methods: Retrospective study of radiographic data analysis. Data were collected from 31 radiographic studies of patients with thoracolumbar spine fracture and distributed to a team involving spinal surgeons and residents. The fractures were classified according to the AO/Magerl and AOSpine classifications. Statistical analysis was performed using the Cohen Kappa test to assess the coefficient of concordance. Results: The Kappa value for interobserver concordance of $\mathrm{AO} / \mathrm{Magerl}$ classification was $\kappa=0.70$ and standard deviation was 0.16. For the AOSpine classification, we observed $\kappa=0.76$, both with significance level $\alpha=0.05$ and $\mathrm{P}<0.001$. Conclusions: We conclude that the interobserver concordance of the new AOSpine classification is similar to the AO/Magerl classification. This conclusion reinforces the reproducibility of the new AOSpine classification. Level of evidence: IV,Type of Study: Case series.
\end{abstract}

Keywords: Spine; Spinal fractures; Spinal injuries.

\section{RESUMO}

Objetivo: Avaliar a reprodutibilidade e a força de concordância interobservador entre as classificações AO/Magerl AOSpine para fraturas da coluna toracolombar. Materiais e Métodos: Estudo retrospectivo de análise de dados radiográficos. Foram levantados dados de 31 estudos radiográficos de pacientes com fratura da coluna toracolombar e distribuídos para uma equipe envolvendo cirurgiões de coluna vertebral e residentes. As fraturas foram classificadas segundo as classificações AO/Magerl AOSpine. A análise estatística foi realizada utilizando o teste de Cohen Kappa para a avaliação da força de concordância. Resultados: O valor de Kappa para concordância interobservador da classificação AO/Magerl foi de $\kappa=0,70$ e desvio padrão 0,16. Para a classificação AOSpine se observou $\kappa=0,76$, ambos com nível de significância $\alpha=0,05$ e $P<0,001$. Conclusão: Concluímos que a concordância interobservador da nova classificação AOSpine é semelhante à classificação AO/ Magerl. Tal conclusão reforça a reprodutibilidade da nova classificação AOSpine. Nível de evidência: IV,Tipo de Estudo: Série de casos.

Descritores: Coluna vertebral; Fraturas da coluna vertebral; Traumatismos da coluna vertebral.

\section{RESUMEN}

Objetivo: Evaluar la reproducibilidad y el coeficiente de concordancia interobservador entre las clasificaciones AO/Magerl y AOSpine para fracturas de la columna toracolumbar. Métodos: Estudio retrospectivo de análisis de datos radiográficos. Se colectaron datos de 31 estudios radiográficos de pacientes con fractura de la columna toracolumbar que fueron distribuidos a un equipo que involucró a cirujanos de columna vertebral y residentes. Las fracturas se clasificaron de acuerdo a las clasificaciones AO/Magerl y AOSpine. El análisis estadístico se realizó mediante la prueba Kappa de Cohen para evaluar el coeficiente de concordancia. Resultados: El valor de Kappa para concordancia interobservador de la clasificación AO/Magerl fue $\kappa=0,70$ y desviación estándar de 0,16. Para la clasificación AOSpine se observó $\kappa=$ 0,76, ambos con nivel de significación $\alpha=0,05$ y $P<0,001$. Conclusiones: Concluimos que la concordancia interobservador de la nueva clasificación AOSpine es similar a la clasificación AO/Magerl. Esta conclusión refuerza la reproducibilidad de la nueva clasificación AOSpine. Nivel de evidencia: IV, Tipo de estudo: Serie de casos.

Descriptores: Columna vertebral; Fracturas de la columna vertebral; Traumatismos vertebrales.

\section{INTRODUCTION}

An ideal system for the classification of thoracolumbar spine fractures should guide treatment according to the natural history of the injuries, in addition to facilitating scientific academic communication. The classification should also be comprehensive, intuitive, and of simple reproducibility. Currently, no classification system fully satisfies these criteria. ${ }^{1}$
Thoracolumbar spine fracture classification systems are considered necessary tools in the diagnosis, staging, selecting the treatment protocol, and defining the expected outcome of the different treatment options.

Thoracolumbar spine injuries present an even greater challenge to the development of a comprehensive classification system due to the involvement of soft tissue structures, as well as to the different 
fracture patterns of the bones involved. Thoracolumbar spine fractures, therefore, are a diverse category of injuries to a complex structure with different susceptibility to lesions and different healing potentials. ${ }^{1-5}$

Many spine fracture classifications have been developed since 1949, each one with its own characteristics that consider stability, the trauma mechanism, neurological and ligament lesions, the concept of spines, and the morphology of bone lesions, with the goal of better understanding the complex presentation of each fracture and to standardize the treatment protocol of professionals. ${ }^{3}$ Despite the development of numerous classifications, few were validated prior to being promoted and accepted by medical society. ${ }^{4}$

Several thoracolumbar spine fracture classifications based on different criteria were developed and the influence of propaedeutic progress and development of techniques to treat these injuries is evident.

Böhler et al. published a classification that differentiated thoracolumbar spine fractures from a morphological and pathogenic perspective. ${ }^{6}$ The fractures were divided into five different types and their respective subdivisions based on radiographic information. The descriptions of the fractures covered most of the types of fracture that can occur, many of which were represented in more recent classification systems.

Nicoll used morphological criteria and classified fractures into four types: ventral wedging, lateral wedging, fracture-luxation, and isolated arc fractures. ${ }^{7}$ Fracture stability was related to the integrity of the interspinous ligament and to whether the rotation force, acting on the spine, would produce unstable lesions.

Holdsworth described a two-spine model: anterior (vertebral body, intervertebral disc, anterior and posterior longitudinal ligaments) and posterior (facet joints and facet joint capsule, interspinous and supraspinous ligaments, and yellow ligament), recognizing the importance of the posterior ligament complex acting as a tension band in the stabilization of the vertebral segment. ${ }^{8}$

Louis introduced a system using three spines (one anterior and two posterior), drawing an analogy between the vertebral segment and a three-legged chair. The anterior spine was made up of the body and the intervertebral disc, and the posterior spine of the facet joints and the joint processes. The lamina and the pedicles provided additional stability for the spines in this model. ${ }^{9}$

In 1994, a classification system was proposed by the AO group (Arbeitsgemeinschaft für Osteosynthesefragen) resulting from a review of 1445 patients over a period of 10 years. ${ }^{2}$ This plan considered the morphological aspect in radiographs (including the extent of soft tissue involvement), the injury mechanisms, and the progressive severity of the injury. Three main injury types are defined by common morphological characteristics and a common force. The type of classification (A, B, C) depends primarily on the mechanical integrity of the posterior spine.

An intact posterior spine differentiates type A lesions from the more serious types $B$ and $C$. Although some studies emphasize that evidence of transverse plane soft tissue involvement is a determinant in the classification of type level, the integrity of the posterior spine was deduced indirectly from radiography and computed tomography in the original series. Magnetic resonance was able to detect ligament injuries associated with fractures of the thoracic and lumbar spines in experimental and clinical studies. ${ }^{10-13}$ It has been suggested that future classifications should include magnetic resonance to better assess findings of soft tissue lesions. ${ }^{14-15}$

In 2005, a new classification system, known as the Thoracolumbar Injury Classification and Severity Score (TLICS/TLISS), ${ }^{6}$ was introduced by Vaccaro et al. following a review of 127 cases of thoracolumbar fractures by 40 experienced surgeons from 15 different institutions. This system is mainly based on three variables (morphology of the fracture, integrity of the posterior ligament complex, and the neurological profile) divided into subgroups which are awarded points according to the impairment of each of these variables. The treatment indication is influenced and guided by the sum of the points.

Like the AO group classification, the morphological analysis of the fracture is subclassified into three different types according to the main trauma mechanism and the radiological aspect of the injury: compression, rotation-translation, and distraction.

Although the AO/Magerl and the thoracolumbar lesion (TLICS) classifications are known systems for describing thoracolumbar fractures, neither of them has achieved universal adoption. This lack of consensus limits communication among clinics and researchers, the study of these lesions, and the development of treatment algorithms.

The AOSpine Trauma Knowledge Forum, an international group of academic spine surgeons, was charged with developing and validating a classification system that incorporates both the morphology of the fracture and the relevant clinical factors for making a surgical decision with the presence of neurological deficits. The objective of this effort was to develop a widely-accepted, comprehensive, and simple classification system, with intra- and interobserver reliability, acceptable for clinical and research use. ${ }^{16}$

To this end, Vaccaro et al. prepared a system with three basic morphological injury types, similar to the AO/Magerl system, that indicates the increasing severity of the lesion, incorporates features of the last two classification systems (AO/Magerl and TLCIS), takes the neurological status into account, and offers specific modifiers that contribute towards making a decision.

The objective of this study was to assess reproducibility and the strength of interobserver agreement between the Arbeitsgemeinschaft für Osteosyntesefragen (AO/Magerl) and AOSpine Thoracolumbar Spine Injury Classification System (AOSpine) for thoracolumbar fractures.

\section{METHODS}

This was a retrospective study that evaluated imaging exams, approved by the Institutional Review Board as protocol number $022704 / 2016$. The ICF was not required because this was only an analysis of images archived in our service.

A description of the morphological types and subtypes of the $\mathrm{AO} / \mathrm{Magerl}$ and AOSpine classifications was presented to the study participants, including the original publications, graphic representations and drawings, in addition to radiographic image examples.

A total of 31 patients attended at the Spine Service of the IOTNitória Apart Hospital and diagnosed with thoracolumbar spine fractures had their high-quality digital radiographs archived and distributed among three spine specialists and two spine residents. The selected images comprised all degrees of injuries. The inclusion criteria were 1) adult patients with a history of thoracolumbar spine fracture, 2) absence of systemic comorbidities, 3) absence of pathological or osteoporotic fractures or fractures resulting from firearm projectiles. The exclusion criteria were 1) poor radiographic conditions for analysis and correct measurement of the vertebral parameters, 2) isolated fractures of the transverse and spinous processes.

The unidentified patient material was sent to the evaluators in random folders containing the anteroposterior and lateral view radiographs of the thoracolumbar spine for each clinical case. The neurological profile from the preoperative evaluation was included for each case and was the only data provided. A simple questionnaire for the evaluators to classify each clinical case using the AO/Magerl and AOSpine criteria was also sent.

The responses were sent to the investigator, who evaluated the interobserver concordance of the AO/Magerl and AOSpine systems.

The $\mathrm{AO} / \mathrm{Magerl}$ interobserver concordance was performed for the three types (A, B, and $C$ ), the nine groups (A1, $A 2, A 3, B 1, B 2, B 3, C 1$, $C 2, C 3)$, as well as for the 25 subgroups (A1.1, A1.2, A1.3, A2.1, etc.).

The interobserver concordance of the AOSpine classification was performed for the three types $(A, B$, and $C)$ and eight groups ( $A 1$, A2, A3, A4, B1, B2, B3, and C).

The characterization of the observers' classifications of the thoracolumbar fractures (AO/Magerl and AOSpine) was performed using frequency observed (Figures 1 and 2). To determine the interobserver concordance, we used the Cohen Kappa (к) measurements: minimum, maximum, and measures of central tendency and variability (Figure 3). The Landis and Koch parameters were used for the evaluation of the degree of this measurement in which values less than 0.39 are considered to be poor concordance, from 0.40 to 0.59 moderate, 0.60 to 0.79 substantial, and 0.80 or greater to be perfect concordance. ${ }^{17}$ The estimated gross measure of association was calculated with a confidence interval $(\mathrm{Cl})$ of $95 \%$ and a significance level of 0.05 . 


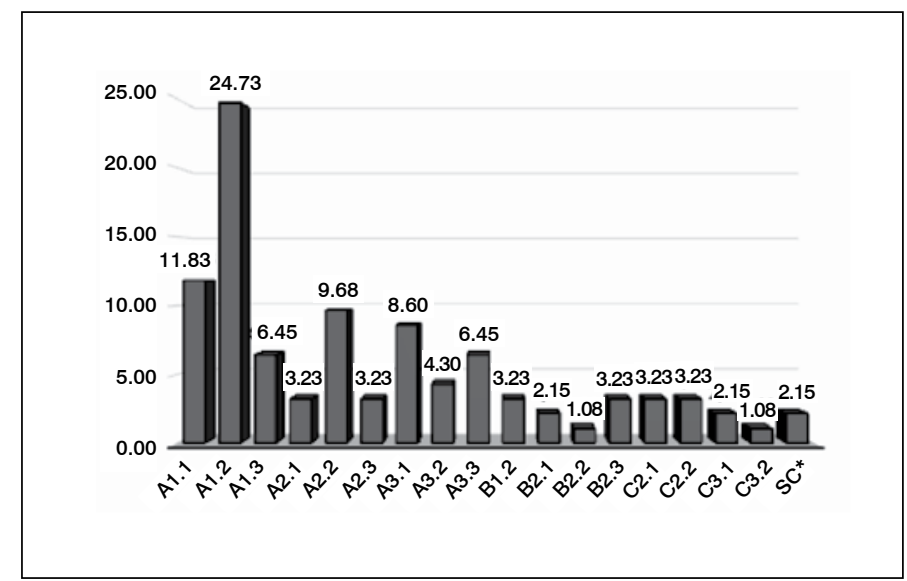

Figure 1. Characterization of the AO Magerl classification.

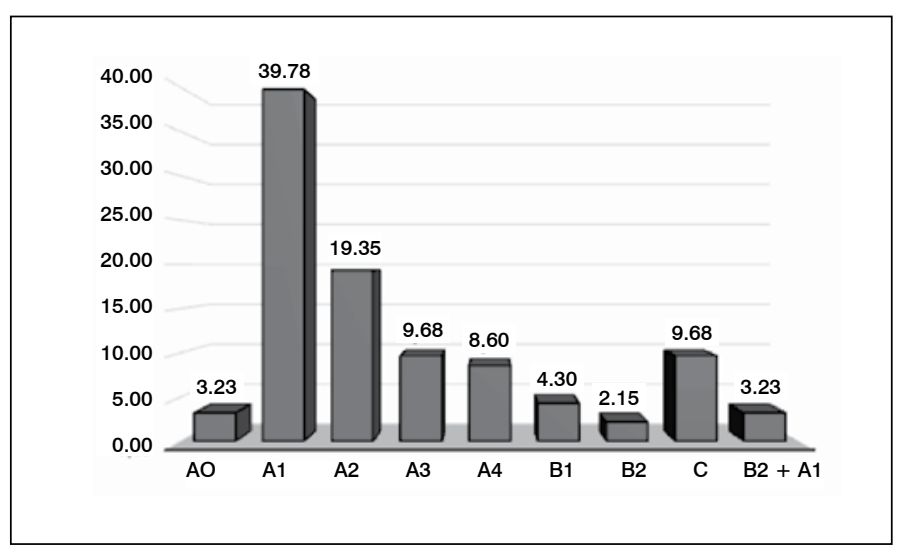

Figure 2. Characterization of the AO Spine classification.

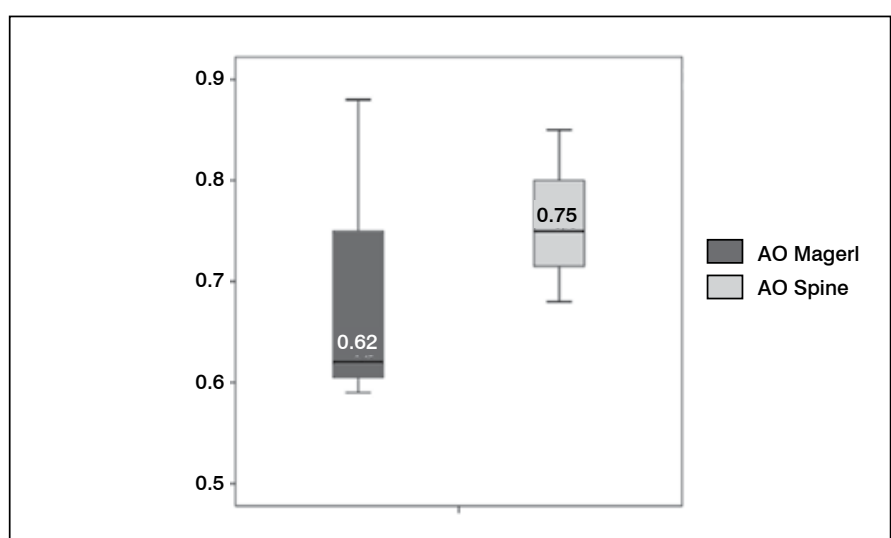

Figure 3. Characterization of the Kappa statistic values in the AO Magerl and AO Spine classifications of thoracolumbar spine fractures.

\section{RESULTS}

The most observed $\mathrm{AO} /$ Magerl classification thoracolumbar fracture group was A1.2 (24.73\%), followed by A1.1 (11.83\%) and A2.2 (9.62\%). For the AOSpine classification, $\mathrm{A} 1$ (39.78\%) was the most frequently occurring group, followed by A2 (19.35\%), and by A3 and C (9.68\%) (Table 1).

The interobserver concordance Kappa values of the AO/Magerl classification were minimum 0.59 , maximum 0.88 , median 0.62 , mean 0.70 , and standard deviation 0.16 . For the AOSpine classification, we observed minimum 0.68, maximum 0.85, median 0.75 , mean 0.76 , and standard deviation 0.09, with a significance level of $\alpha=0.05$ and $\mathrm{P}<0.001$ (Table 2).

The interobserver concordance obtained for the AO/Magerl and AOSpine classifications are described in Table 3 and Figure 4.
Table 1. Characterization of the MAGERL and AO spine classifications of thoracolumbar spine fractures.

\begin{tabular}{|c|c|c|c|}
\hline & Subtype & $\mathrm{n}$ & $\%$ \\
\hline \multirow{18}{*}{ AO Magerl } & A1.1 & 11 & 11.83 \\
\hline & A1.2 & 23 & 24.73 \\
\hline & A1.3 & 6 & 6.45 \\
\hline & A2.1 & 3 & 3.23 \\
\hline & A2.2 & 9 & 9.68 \\
\hline & A2.3 & 3 & 3.23 \\
\hline & A3.1 & 8 & 8.60 \\
\hline & A3.2 & 4 & 4.30 \\
\hline & A3.3 & 6 & 6.45 \\
\hline & B1.2 & 3 & 3.23 \\
\hline & B2.1 & 2 & 2.15 \\
\hline & B2.2 & 1 & 1.08 \\
\hline & B2.3 & 3 & 3.23 \\
\hline & $\mathrm{C} 2.1$ & 3 & 3.23 \\
\hline & C2.2 & 3 & 3.23 \\
\hline & C3.1 & 2 & 2.15 \\
\hline & C3.2 & 1 & 1.08 \\
\hline & $\mathrm{SC}^{*}$ & 2 & 2.15 \\
\hline \multirow{9}{*}{ AO Spine } & A0 & 3 & 3.23 \\
\hline & A1 & 37 & 39.78 \\
\hline & A2 & 18 & 19.35 \\
\hline & A3 & 9 & 9.68 \\
\hline & A4 & 8 & 8.60 \\
\hline & B1 & 4 & 4.30 \\
\hline & B2 & 2 & 2.15 \\
\hline & $\mathrm{C}$ & 9 & 9.68 \\
\hline & $\mathrm{B} 2+\mathrm{A} 1$ & 3 & 3.23 \\
\hline
\end{tabular}

*Unclassified. Source: Vitória Apart Hotel, Institute of Orthopedics and Traumatology, Spine Service.

Table 2. Characterization of the kappa statistic values in the ao magerl and ao spine thoracolumbar spine fracture classifications.

\begin{tabular}{c|c|c}
\hline & AO Magerl $^{*}$ & AO Spine* $^{*}$ \\
\hline Minimum & 0.59 & 0.68 \\
\hline Maximum & 0.88 & 0.85 \\
\hline Median & 0.62 & 0.75 \\
\hline Mean & 0.70 & 0.76 \\
\hline Standard deviation & 0.16 & 0.09
\end{tabular}

Table 3. Interobserver concordance of the ao magerl and ao spine classifications.

\begin{tabular}{c|c|c|c}
\hline & Examiner & Kappa $^{*}$ & $\mathbf{n ~ ( \% ) ^ { * * }}$ \\
\hline \multirow{4}{*}{ AO Magerl } & $\mathrm{A} \times \mathrm{B}$ & 0.59 & $21 / 31(67.74)$ \\
\cline { 2 - 4 } & $\mathrm{A} \times \mathrm{C}$ & 0.62 & $22 / 31(70.97)$ \\
\cline { 2 - 4 } & $\mathrm{B} \times \mathrm{C}$ & 0.88 & $28 / 31(90.32)$ \\
\cline { 2 - 4 } & Mean & 0.70 & $23.7 / 31(76.34)$ \\
\hline \multirow{4}{*}{ AO Spine } & $\mathrm{A} \times \mathrm{B}$ & 0.68 & $22 / 31(70.97)$ \\
\cline { 2 - 4 } & $\mathrm{A} \times \mathrm{C}$ & 0.75 & $24 / 31(77.42)$ \\
\cline { 2 - 4 } & $\mathrm{B} \times \mathrm{C}$ & 0.85 & $27 / 31(87.10)$ \\
\cline { 2 - 4 } & Mean & 0.76 & $24.3 / 31(78.49)$ \\
\hline
\end{tabular}

*Significance level of $5 \%$ and $p$ value $<0.001$ in all cases; ** Interobserver concordance. Source: Vitória Apart Hotel, Orthopedics and Traumatology Institute, Spine Service.

\section{DISCUSSION}

An ideal classification system presents an objective and communicable categorization of the object of the study. In addition to prognostic factors, it should provide a guide for the proper handling of those submitted to the proposed treatment. To date, few classification systems include characteristics that help the attending physician to define the best treatment option for the injury.

A study to evaluate the reproducibility of the Denis classification reported an interobserver concordance of $\kappa=0.71 .^{18}$

The AO/Magerl system, introduced in 1994, is the most often used classification system because it is more inclusive than previous classifications and because of its higher degree of correlation with the greater risk of neurological damage, as well as because of the greater chance of the failure of conservative treatment. The same previously mentioned study reported an interobserver concordance of $\kappa=0.48{ }^{18}$ Our study observed an interobserver concordance of $\kappa=0.70$. 


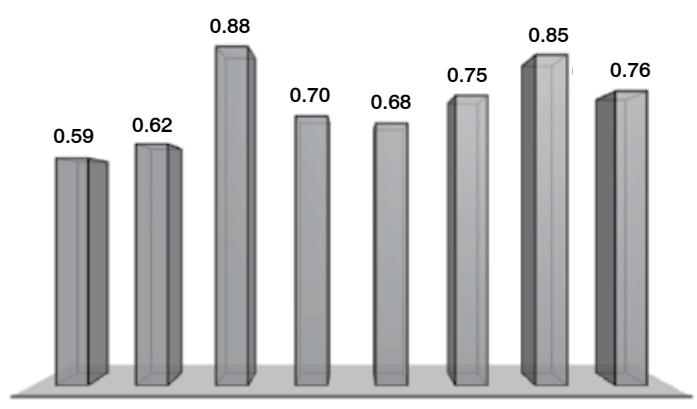

Figure 4. Interobserver concordance of the AO Magerl and AO Spine classifications.

Vaccaro et al. observed slight interobserver concordance among five evaluators using the TLISS (Thoracolumbar Injury Severity Score) system. ${ }^{19}$ The interobserver concordance of the TLICS/TLISS classifications ranges from slight to moderate in most studies. ${ }^{20-21}$

As regards thoracolumbar fractures, several publications show the progressive evolution of the classification. On the other hand, they challenge the application of the new method in the scientific community to the disinterest of the most expert surgeons with extensive skill and experience in the older classification systems. A study published by Sadiqi et al. demonstrated lower reproducibility of the AOSpine classification among more experienced surgeons. ${ }^{22}$ Other studies reported moderate interobserver concordance, with great difficulty agreeing on the newer subtypes in particular. ${ }^{23-26}$ Our study had an interobserver concordance value of $\kappa=0.06$ for the AOSpine classification. There is no consensus around the $\kappa$ values that ought to be considered acceptable for fracture classification systems, however, a value of $\kappa>0.55$ has been suggested. ${ }^{21}$

We recognize several limitations in our study, one up front being the different levels of training and familiarity with the two classification systems studied. We also understand that a classification system should be reproducible regardless of experience. The retrospective study was based only on radiographic images, reducing the reliability of the images presented, since the patterns of soft tissue lesions associated with the fractures may not be sufficiently depicted. On the other hand, it allowed the standardization of the sample to be maintained, eliminating any quality bias within the sample studied.

Our study collaborated with the reproducibility of the new AOSpine classification, since the moderate interobserver concordance results were similar to the results of the $\mathrm{AO} / \mathrm{Magerl}$ classification. We attribute this fact to the routine use of the two classification systems analyzed and the considerable familiarity with using it in a reliable form. We were not surprised by the moderate reproducibility results because the team that analyzed the images was made up of a heterogeneous group of experienced surgeons and residents at different training levels.

\section{CONCLUSIONS}

The interobserver concordance of the new AOSpine classification is similar to that of the already established AO/Magerl classification, even among a heterogeneous group of evaluators. Our conclusion reinforces the reproducibility of the new AOSpine classification.

\section{BUDGETARY STATEMENT}

I declare that the research protocol had no sponsor, any and all expenses related to its development being the sole responsibility of the research team.

\section{ACKNOWLEDGEMENTS}

Thanks to the evaluators, Dr. Juliano Rodrigues dos Santos and Dr. Guilherme Galito Henriques.

All authors declare no potential conflict of interest related to this article.

CONTRIBUTION OF THE AUTHORS: Each author made significant individual contributions to this manuscript. ALPV (0000-0002-2947-9102)*, JRS

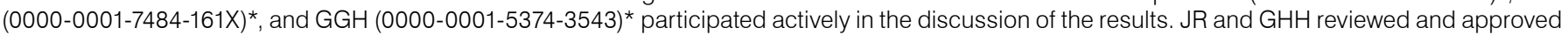
the final version of the study. ${ }^{*}$ ORCID (Open Researcher and Contributor ID).

\section{REFERENCES}

1. Audige $L$, Bhandari $M$, Hanson $B$, Kellam J. A concept for the validation of fracture classifications. J Orthop Trauma. 2005;19(6): 401-6.

2. Magerl F, Magerl F, Aebi M, Gertzbein SD, Harms J, Nazarian S. A comprehensive classification of thoracic and lumbar injuries. Eur Spine J. 1994:3(4):184-201.

3. Denis F. The three column spine and its significance in the classification of acute thoracolumbar spinal injuries. Spine (Phila Pa 1976). 1983;8(8):817-31.

4. Hu R, Mustard CA, Burns C. Epidemiology of incident spinal fracture in a complete population. Spine (Phila Pa 1976). 1996:.21(4):492-9.

5. Ferguson $\mathrm{RL}$, Allen $\mathrm{BL} \mathrm{J}$ r. A mechanistic classification of thoracolumbar spine fractures. Clin Orthop Relat Res. 1984;(189):77-88.

6. Vaccaro AR, Lehman RA Jr, Hurlbert RJ, Anderson PA, Harris M, Hedlund R et al. A new classification of thoracolumbar injuries: the importance of injury morphology, the integrity of the posterior ligamentous complex, and neurologic status. Spine (Phila Pa 1976). 2005;30(20):2325-33

7. Nicoll EA. Fractures of the dorso-lumbar spine. J Bone Joint Surg Br. 1949;31B(3):376-94.

8. Holdsworth F. Fractures, dislocations, and fracture-dislocations of the spine. J Bone Joint Surg Am. 1970:52(8):1534-51.

9. Louis R. Spinal stability as defined by the three-column spine concept. Anat Clin. 1985; 7(1):33-42.

10. Kliewer MA, Gray L, Paver J, Richardson WD, Vogler JB, McElhaney JH, et al. Acute spinal ligament disruption: MR imaging with anatomic correlation. J Magn Reson Imaging 1993; 3(6):855-61.

11. Oner FC, Rijt RHHvd, Ramos LMP, Groen JG, Dhert JA, Verbout AJ et al. Correlation of MR images of disc injuries with anatomic sections in experimental thoracolumbar spine fractures. Eur Spine J. 1999;8(3):194-8.

12. Petersilge CA, Pathria MN, Emery SE, MasarykTJ. Thoracolumbar burst fractures: evaluation with MR imaging. Radiology. 1995:194(1): 49-54.

13. Terk MR, Hume-Neal M, Fraipont M, Ahmadi J, Colletti PM. Injury of the posterior ligament complex in patients with acute spinal trauma: evaluation by MR imaging. AJR Am J Roentgenol. 1997;168(6):1481-6.

14. Oner FC, va Gils AP, Dhert WJ, Verbout AJ. MRI findings of thoracolumbar spine fractures: a categorisation based on MRI examinations of 100 fractures. Skeletal Radiol. 1999:28(8):433-43.

15. Saifuddin A, Noordeen $H$, Taylor BA, Bayley I. The role of imaging in the diagnosis and management of thoracolumbar burst fractures: current concepts and a review of the literature. Skeletal Radiol. 1996;25(7): 603-13

16. Vaccaro AR, Oner C, Kepler CK, Dvorak M, Schnake K, Bellabarba C. AOSpine thoracolumbar spine injury classification system: fracture description, neurological status, and key modifiers. Spine (Phila Pa 1976). 2013;38(23):2028-37.

17. Landis JR, Koch GG. The measurement of observer agreement for categorical data. Biometrics. 1977;33(1):159-74.

18. Wood KB, Khanna G, Vaccaro AR, Arnold PM, Harris MB, Mehbod AA. Assessment of two thoracolumbar fracture classification systems as used by multiple surgeons. J Bone Joint Surg Am. 2005; 87(7): 1423-9.

19. Vaccaro AR, Baron EM, Sanfilippo J, Jacoby S, Steuve J, Grossman E. Reliability of a novel classification system for thoracolumbar injuries: the Thoracolumbar Injury Severity Score. Spine (Phila Pa 1976). 2006:31(11 Suppl):S62-9.

20. Koh YD, Kim DJ, Koh YW. Reliability and Validity of Thoracolumbar Injury Classification and Severity Score (TLICS). Asian Spine J. 2010;4(2):109-17.

21. Oner FC, Ramos L, Simmermacher R, Kingma L, Diekerhof $C$, Dhert W. Classification of thoracic and lumbar spine fractures: problems of reproducibility. A study of 53 patients using CT and MRI. Eur Spine J. 2002; 11(3):235-45.

22. Sadiqi S, Oner FC, Dvorak MF, Arabi B, Schroeder GD, Vaccaro AR. The Influence of Spine Surgeons' Experience on the Classification and Intraobserver Reliability of the Novel AOSpine Thoracolumbar Spine Injury Classification System-An International Study. Spine (Phila Pa 1976). 2015;40(23):E1250-6.

23. Kepler CK, Vaccaro AR, Koener JD, Dvorak M, Kandiziora F Rajasekaran S, et al. Reliability analysis of the AOSpine thoracolumbar spine injury classification system by a worldwide group of naive spinal surgeons. Eur Spine J. 2016; 25(4):1082-6.

24. Kaul R, Cnhabra HS, Vaccaro AR, Abel R, Tuli S, Shelty AP. Reliability assessment of AOSpine thoracolumbar spine injury classification system and Thoracolumbar Injury Classification and Severity Score (TLICS) for thoracolumbar spine injuries: results of a multicentre study. Eur Spine J.2017; 26(5):1470-6.

25. Cheng J, Liu P, Sun D, Qin T, Ma Z, Liu J. Reliability and reproducibility analysis of the AOSpine thoracolumbar spine injury classification system by Chinese spinal surgeons. Eur Spine J. 2017:26(5):1477-82.

26. Urrutia J, ZamoraT,Yurac R, Campos M, Palma J, Mobarec S. An independent interobserver reliability and intraobserver reproducibility evaluation of the new AOSpineThoracolumbar Spine Injury Classification System. Spine (PhilaPa 1976). 2015;40(1):E54-8. 